\title{
EL NEOCONSTITUCIONALISMO PRINCIPIALISTA EN LA ASAMBLEA NACIONAL CONSTITUYENTE DE 1991*
}

\author{
Sergio Estrada Vélez**
}

Fecha de recibido: 5 de marzo de 2014

Fecha de aprobado: 29 de mayo de 2014

Artículo de Reflexión

Forma de citación: Estrada, S. (2014). El neoconstitucionalismo principialista en la Asamblea Nacional Constituyente de 1991. Revista Prolegómenos. Derechos y Valores, 17, 33, 27-42.

\section{Resumen}

A partir de una observación a la enseñanza y práctica del derecho, se advierte que aún no se ha desarrollado una teoría de principios acorde al contexto nacional. Un sector de la doctrina los asume como principal paradigma normativo, con funciones políticas (criterios de legitimación racional), axiológicas (concreción de valores) y jurídicas (criterios de validez material); otro, indica que son criterios auxiliares de la actividad judicial. Esa confusión repercute negativamente en el razonamiento jurídico requerido, para una recta y eficaz administración de justicia en el marco del Estado social, y justifica un estudio detallado de la noción de principios asumida por la Asamblea Nacional Constituyente de Colombia de 1991. De otro lado, la escasa doctrina nacional se ha limitado, en términos generales, a reproducir las ideas de importantes filósofos del derecho escritas al margen de los requerimientos que impone el modelo político colombiano. Confusión y descontextualización justifican el objetivo principal de este artículo: facilitar la comprensión de la naturaleza y funciones de los principios jurídicos en nuestro Estado social de derecho a través de la indagación de la voluntad del constituyente. Esto ayudará a superar la contradictoria jurisprudencia sobre el tema y la errada comprensión que se ha tenido del artículo 230 de la Constitución Política. Para lograr ese propósito, se acudió a un método de investigación documental de las gacetas de la Asamblea Nacional Constituyente de 1991, los rollos de microfilmación que reposan en el Archivo General de la Nación y a entrevistas realizadas a algunos ex constituyentes.

\section{Palabras clave:}

Principios morales, principios jurídicos, neoconstitucionalismo, validez material.

Resultado del proyecto de investigación titulado «La participación ciudadana en el proceso constituyente de 1991», la cual terminó en el mes de febrero de 2014, fue financiada por COLCIENCIAS y la Universidad de Medellín y desarrollada por el Grupo de Investigaciones Jurídicas de la Facultad de Derecho de dicha Universidad. El autor participó en calidad de coautor.

* Abogado, especialista en Derecho constitucional, especialista en Argumentación jurídica (España); Diploma de Estudios Avanzados Universidad de León (España); Magister, Estudios de doctorado Universidad de Buenos Aires. Profesor de Teoría General del Derecho, Principialística y Hermenéutica Jurídica de la Universidad de Medellín; autor de los textos La Excepción de Principialidad, Temis: Bogotá, 2000; y Los principios Jurídicos y el Bloque de Constitucionalidad, $3^{\mathrm{a}}$ ed. Universidad de Medellín, 2011. Correo electrónico: siestrada@udem.edu.co 


\title{
PRINCIPLIST NEO-CONSTITUTIONALISM ON THE 1991 NATIONAL CONSTITUENT ASSEMBLY OF COLOMBIA
}

\begin{abstract}
From observing the teaching and practice of law, it is found that a theory of principles has not been developed in accordance to the national context. A section of the doctrine assumes them as a main normative paradigm, with political (rational legitimacy criteria), axiological (value precision) and legal (material validity criteria) functions; the other one indicates that they are auxiliary criteria of judicial activity. This confusion has a negative impact on the required legal reasoning for a correct and effective administration of justice in the context of the social state and justifies a detailed study of the principles notion assumed by the 1991 National Constituent Assembly of Colombia. In addition, a weak domestic doctrine has been limited, in general, to reproduce the ideas of major law philosophers written outside of the requirements imposed by the Colombian political model. Both confusion and decontextualization justify the main objective of this article: to facilitate the comprehension of the legal principles in the Colombian social rule of law, their nature and functions by researching of the will of the constituent. This will aid to overcome the contradictory jurisprudence on the subject and the incorrect comprehension of Article 230 of the Constitution. For this purpose, a documentary research method of the National Constituent Assembly of 1991 official journals, the microfilm rolls that rest in the General Archive of the Nation and interviews with some former constituents was used.
\end{abstract}

\section{Keywords:}

Moral principles, legal principles, neo-constitutionalism, substantive validity.

\section{PRINCIPIALISTA NEO-CONSTITUCIONALISMO NA ASSEMBLÉIA NACIONAL CONSTITUINTE DE 1991 DA COLÔMBIA}

\begin{abstract}
Resumo
Observando o ensino ea prática da lei, verifica-se que a teoria dos princípios de não ter sido desenvolvido de acordo com o contexto nacional. Uma parte da doutrina consideralos como principal paradigma normativo, com critérios racionais (legitimidade) políticas, axiológica (precisão de valor) e os critérios de validade (materiais) funções legais; a outra indica que eles são critérios auxiliares da atividade judicial. Esta confusão tem um impacto negativo sobre o raciocínio jurídico necessário para uma administração correta e eficaz da justiça no contexto do Estado social e justifica um estudo detalhado da noção princípios assumidos pela Assembléia Nacional Constituinte de 1991 da Colômbia. Além disso, a doutrina nacional fraco tem sido limitado, em geral, para reproduzir as idéias dos grandes filósofos lei escrita fora das exigências impostas pelo modelo político colombiano. Ambos confusão e descontextualização justificar o objetivo principal deste artigo: para facilitar a compreensão dos princípios jurídicos na regra colombiano social de direito, sua natureza e funções, pesquisando da vontade do constituinte. Isto ajudará a superar a jurisprudência contraditória sobre o assunto ea compreensão errada do
\end{abstract}


artigo 230 da Constituição. Para isso, um método da Assembléia Nacional Constituinte de 1991 jornais oficiais pesquisa documental, o microfilme que rola resto no Arquivo Geral da Nação e entrevistas com alguns ex-constituintes foi usado.

\section{Palavras-Chave:}

Os princípios morais, Princípios legais, Neo-constitucionalismo, Validade substantiva

\section{INTRODUCCIÓN}

La incorporación de un modelo de Estado constitucional y social de derecho representó una transformación sustancial en el razonamiento jurídico, entendido este como el conjunto de los elementos que caracterizan la creación, interpretación y aplicación del derecho. Se pasó de un razonamiento soportado en la racionalidad que enfatizaba en aspectos lógicos o teóricos del derecho, a un razonamiento regido por la razonabilidad o logos de lo humano (Recasens, 1956, p. 131), que acude a aspectos externos al derecho como el sentido común, la conveniencia o juicios de justicia basados en una moral social.

Ese cambio promovió una modificación, todavía en ciernes, de la Teoría del derecho en aspectos tan importantes como la norma jurídica, las fuentes del derecho y la validez jurídica, entre otros. De una caracterización de la norma bajo criterios lógico-estructurales concretados en una estructura de supuesto de hecho, cópula y consecuencia (normas tipo regla), se pasa a la noción de principios jurídicos entendidos como normas jurídicas carentes de la misma estructura lógica. En relación a las fuentes, el espacio reservado al legislador para la producción del derecho empieza a ser compartido con la jurisdicción. Frente al concepto de validez, se afirma que ella no puede depender solamente de criterios formales referidos al órgano de producción $y$ al procedimiento, sino que debe tener presentes criterios materiales concretados en los principios jurídicos asumidos como normas que condicionan la validez material de las restantes normas del ordenamiento. En este sentido expresa Ferrajoli: «(...) en un ordenamiento dotado de constitución rígida, para que una norma sea válida además de vigente no basta que haya sido emanada con las formas predispuestas para su producción, sino que es también necesario que sus contenidos sustanciales respeten los principios y los derechos fundamentales establecidos en la Constitución» (2001, p. 66).

Esas transformaciones de la teoría del derecho, a partir de la Segunda guerra mundial, dieron lugar a una evolución cualitativa en el razonamiento jurídico. La noción de principios ya no se reduce a la idea de criterios metajurídicos que condicionan moralmente la existencia del derecho o de criterios auxiliares en los casos de ausencia de claridad de la ley, de vacíos o incoherencias del ordenamiento. En el Estado social y constitucional se les reconoce no solo su condición de normas jurídicas sino su función de criterios de validez de las restantes del ordenamiento.

De esta manera, se puede afirmar que el constitucionalismo de posguerra ha impulsado una nueva teoría del derecho aún por definir (García, 2003, p. 160), representada, entre otros aspectos, por la presencia de más principios que reglas, más ponderación que subsunción, mayor relevancia de la función judicial en relación a la potestad del legislador (Prieto, 2003, p. 131-132). Como lo indica Aragón «parece difícil negar que hoy el Derecho de la Constitución es un Derecho "por principios"» (1997, p. 23).

Lo anterior puede ser una síntesis de las transformaciones aparejadas a lo que se ha dado en llamar neoconstitucionalismo, mínima pero suficientemente pertinente para justificar la importancia de un estudio del derecho a partir 
de los principios jurídicos: estos no solo son criterios auxiliares sino parámetros de validez material y herramientas fundamentales para el fortalecimiento de las garantías individuales.

Pese a la relevancia de un estudio de los principios, se puede afirmar que el mismo ha estado atado a una perspectiva eurocéntrica que ha descuidado el contexto político y social de los llamados países del tercer mundo. Prueba de ello es el confuso uso del término neoconstitucionalismo, referido generalmente a las circunstancias que impulsaron el fortalecimiento de la primacía constitucional después de la Segunda guerra mundial, pasando por alto, tanto los constitucionalistas como los teóricos del derecho, que para abordar el neoconstitucionalismo y el papel que cumple el principialismo, es necesario resolver previamente tres interrogantes a la luz de cada realidad política y social: Qué se entiende por «Constitución», por «neo» y por «principios».

Se trata de advertir que no es posible analizar lo que se ha dado en llamar como el principal paradigma normativo (los principios) y su relación con el neoconstitucionalismo, sino se delimita de manera aproximada el sentido de expresiones como «Constitución», «Neo» y «Principios». Esa labor desborda las pretensiones de este artículo que se reducen básicamente a demostrar si el constituyente empleó o no alguna noción de principios en la construcción de la Constitución Política de 1991, pero se debe insistir en que todo intento por describir el neo y los principios exige realizar una aclaración mínima del sentido de ambos términos en la medida en que no están atados a ciertos o únicos acontecimientos históricos, sino que cada contexto político y social ofrece, sin duda, elementos particulares para construir un sentido específico.

La indagación por la existencia y sentido de la noción de principios en los debates de la Asamblea Nacional Constituyente de Colombia de 1991, es pertinente en la medida en que en la actualidad se advierten cuatro serios problemas:

- La presencia de lo que se podría llamar una antinomia jurídica, en tanto que de un lado, se consagra que los principios son normas de derecho natural (artículo 4 de la ley 153 de 1887) y herramientas auxiliares de la función judicial (artículo 230 de la Constitución Política de Colombia de 1991), pero, de otro, se evidencia una clara tendencia de nuestro legislador en reconocer el carácter prevalente de los principios consagrados en la respectiva ley y en la Constitución Política.

- La imposibilidad de construir a partir de las sentencias de la Corte Constitucional una línea jurisprudencial que dé cuenta de la naturaleza y funciones de los principios, en general de una noción que sea coherente con el Estado constitucional y social de derecho. Ello se advierte, a modo de ejemplo, en la Sentencia C-083 de 1995 M.P. Carlos Gaviria Díaz, en la que esa alta corporación indicó que la expresión «principios generales del derecho» en el artículo 230 de la Constitución Política -en adelante C.P.- se debe entender como criterios extrasistemáticos, esto es, que están por fuera del ordenamiento, y, de otro lado, en la Sentencia T-406 de 1992 M.P. Ciro Angarita Barón, se indica que los principios son normas jurídicas que en el Estado constitucional adquieren una importancia excepcional. Aumenta la confusión una lectura a la Sentencia C-067 de 2003 M.P. Marco Gerardo Monroy Cabra, en la que la Corte Constitucional describe las funciones de las normas que pertenecen al Bloque de constitucionalidad debiéndose resaltar la función limitadora o validadora, citando para ello un texto de Norberto Bobbio titulado Los Principios generales del derecho.

Es clara la ausencia de una idea básica de principios o, en términos más precisos, es inocultable la presencia de muchas nociones de principios, lo que permite clamar por una sentencia unificadora que aborde lo que se podría afirmar como los dos aspectos básicos de la teoría principial: su naturaleza y funciones en el Estado social y constitucional de derecho. Si nuestra Corte Constitucional alcanzara a dimensionar los daños que en la práctica jurídica ha 
ocasionado la presencia de sentencias que reducen la importancia de los principios o de jueces que no los aplican por temor al prevaricato, no prolongaría la expedición de ese tipo de decisión.

- La existencia de una importante pero escasa doctrina en materia de principios. No es prudente tratar de enlistar los autores nacionales que se han dedicado al tema, pero también sería injusto no referenciar algunos de los más relevantes como Valencia Restrepo (2007), Bernal Pulido (2007) y Lopera Mesa (2006). La literatura es poca y parte de la existente está construida sobre alguna de las dos principales propuestas epistemológicas: la Dworkiana o la Alexyana, sin una evaluación de su pertinencia a la luz de las particularidades de nuestro modelo político y jurídico. Si se asumen los principios como paradigma normativo que consagran límites al ejercicio del poder y garantías individuales, no bastará con asumirlos como estándares que han de ser observados por ser «una exigencia de la justicia, la equidad o alguna otra dimensión de la moralidad» (Dworkin, 1984, p. 72) o como mandatos de optimización (Alexy, 1993, p. 86).

- Finalmente, la interpretación literal del artículo 230 de la CP que hace referencia a los principios generales del derecho como criterios auxiliares de la actividad judicial, ha impedido que el operador jurídico, en especial los jueces, contemplen la aplicación de una noción de principios más coherente con las exigencias del Estado social y constitucional.

Para el logro del objetivo propuestos (demostrar si el constituyente empleó o no alguna noción de principios en la construcción de la Constitución Política de 1991), se ofrece al lector este escrito compuesto por cuatro apartes: en el primero, se formulan algunas reflexiones con relación a la idea de neoconstitucionalismo en Colombia, con el fin de demostrar las dificultades de su uso en el contexto nacional cuando se acude a un neoconstitucionalismo ideológico que asume los principios como normas morales o elementos que están por fuera del ordenamiento jurídico; en el segundo, se trata de evidenciar la necesidad de perfilar una noción básica de principios acorde a la realidad nacional bajo esta idea básica: una visión descontextualizada del neoconstitucionalismo y de los principios jurídicos afecta directamente la proposición de criterios de legitimidad racional en el Estado social y constitucional de derecho; en el tercero, se esboza la noción de principios en la Asamblea Nacional Constituyente, con el objeto de demostrar que el énfasis en el discurso político llevó a un involuntario descuido frente al estudio del principal paradigma normativo: los principios jurídicos; en el cuarto, se formulan las conclusiones entre las que se resalta la necesidad de una Asamblea Nacional Jurisprudente con el fin de establecer un «estatuto epistemológico mínimo» que sirva de apoyo a la materialización de la Constitución Política y de fundamentación teórica básica en la formación de nuevos abogados.

\section{EL NEOCONSTITUCIONALISMO EN COLOMBIA}

Este espacio no es suficiente para llevar a cabo un estudio del neoconstitucionalismo en Colombia ${ }^{1}$, pero ello no debe servir de excusa para formular algunas reflexiones que se deben tener en cuenta en el intento por comprender el mismo.

Se ha dado en llamar nuevo constitucionalismo a los cambios en el razonamiento jurídico después de la Segunda guerra mundial, motivados por la necesidad de fortalecer los límites al ejercicio del poder y las garantías individuales. Pero, si se asume que el derecho es un objeto cultural, cuyo contenido depende del contexto y las realidades de cada país, no se puede afirmar que lo que se considera nuevo en Europa debe ser necesariamente nuevo en América.

Así, a modo de ejemplo, si el neoconstitucionalismo se caracteriza básicamente por el refor-

1 Una aproximación en Estrada (2012, p. 513). 
zamiento del carácter de norma de normas de la Constitución y la presencia de principios jurídicos que determinan la validez de las restantes normas del ordenamiento, se puede afirmar que en Colombia ya existían claros indicios de él: El acto legislativo 3 de 1910 consagró en sus artículos 40 y 41 la primacía constitucional y el control concentrado de constitucionalidad ${ }^{2}$. A ello se suma el papel cumplido por la Corte Suprema de Justicia a finales de la década de los cuarenta llamada Corte de Oro en tanto que se propuso «modernizar el derecho y, por lo tanto, afinarlo a las nuevas circunstancias sociales» (López, 2004, p. 314), a través de la defensa de la libre investigación científica y el reconocimiento explícito de una moralización del derecho.

Ello tuvo lugar a través de una jurisprudencia soportada en principios generales del derecho que fue paradigmática dentro del derecho civil y abanderada de una lucha contra el formalismo jurídico. La producción jurisprudencial se soportó en principios generales del derecho para la toma de decisiones correctivas del texto de la ley o complementarias del mismo. Este momento representó una producción jurídica vanguardista en una época en la que primaba el imperio de la ley. Los anteriores son claros ejemplos de una primacía material de la Constitución y del mayor peso de los principios sobre las restantes normas del ordenamiento.

Si el llamado neoconstitucionalismo se concreta en el reforzamiento de la Constitución y en el reconocimiento de los principios como normas

2 Señalan los artículos 40 y 41 de dicho acto legislativo: «Artículo 40. En todo caso de incompatibilidad entre la Constitución y la ley se aplicaran de preferencia las disposiciones constitucionales. Artículo 41. A la Corte Suprema de Justicia se le confía la guarda de la integridad de la Constitución. En consecuencia, además de las facultades que le confieren esta y las leyes, tendrá la siguiente: Decidir definitivamente sobre la exequibilidad de los Actos legislativos que hayan sido objetados como inconstitucionales por el Gobierno, o sobre todas las leyes o decretos acusados ante ella por cualquier ciudadano como inconstitucionales, previa audiencia del Procurador General de la Nación». jurídicas (neo en relación a qué), es claro que en Colombia (neo en relación a quiénes) existieron importantes vestigios con anterioridad al surgimiento del mismo en Europa.

De otro lado, resulta imprescindible advertir que todo intento de definición del neoconstitucionalismo exige una aclaración previa acerca de qué se debe entender por estos tres conceptos: Constitución, constitucionalización y constitucionalismo. A partir de allí, se podrá dar respuesta con mayor claridad a preguntas como qué se entiende por "nuevo", nuevo en relación a qué y nuevo en relación a quienes. En todo caso, no es posible tratar de definir qué es el neoconstitucionalismo sin tener una idea previa de qué es Constitución.

Esta alerta adquiere especial importancia en la medida en que la defensa de cierta noción de Constitución y de constitucionalismo puede generar consecuencias adversas a la misma filosofía constitucional (establecer límites al ejercicio del poder y fortalecer las garantías individuales). En términos más precisos, una defensa de un constitucionalismo ideológico que afirma la primacía sobre el derecho de una moral "concretada» en la Constitución a través de los valores constitucionales, puede generar postulados que en lugar de promover límites al poder alimentan un ejercicio de la discrecionalidad judicial en cabeza de los tribunales constitucionales, a tal nivel, que puede rayar con la arbitrariedad. De allí la importancia de una distinción entre principios y valores sugerida por Kelsen (1995, p. 34-36 y 2008, p. 34-35) y Habermas (1998, p. 327-332).

Por razones de espacio no es posible realizar acá una distinción entre Constitución, constitucionalización y constitucionalismo, pero para los efectos propuestos basta con resaltar el infortunado reduccionismo ontológico y epistemológico en el que caemos los abogados al momento de describir lo que es una Constitución, en tanto que nos sentimos satisfechos con señalar que es la norma de normas. Ello es cierto, pero sin duda insuficiente. El profesor Blanco Valdés 
en su obra El valor de la Constitución (1998, p. 38), da cuenta de dos valores de la Constitución: el político y el jurídico, que se enmarcan en los procesos revolucionarios francés $y$ norteamericano, respectivamente.

Cuando hace referencia al valor político de la Constitución alude a problemas como la configuración, ejercicio y límites del poder, a las relaciones entre el Estado y los administrados, la legitimidad, la participación, el pluralismo, a la eficacia indirecta de la Constitución, etc. Bajo el valor jurídico de la Constitución, se abordan problemas como la noción de norma, las fuentes del derecho, la validez de la norma, la naturaleza de los enunciados constitucionales que consagran valores, directrices y principios, los derechos fundamentales, de los derechos sociales, a su eficacia directa, entre otros.

Pero además del valor político y jurídico de la Constitución, es necesario sumar la existencia de un valor axiológico o moral que surge con los procesos constitucionales de posguerra, caracterizados por la incorporación de valores entendidos como normas objetivas con los que se quería condicionar o limitar el ejercicio del poder. De esta manera, se puede afirmar que si bien la Constitución es norma de normas, no significa que todos sus enunciados son normas jurídicas en la medida en que en ella se encuentran, básicamente, enunciados políticos (directrices), morales (valores) y, por supuesto, jurídicos (principios y reglas). Una cosa es dotar de fuerza vinculante a toda la Constitución y otra muy distinta mutar la naturaleza de algunos de sus enunciados que nunca podrán ser jurídicos por el solo hecho de estar en el texto de la Constitución.

De igual manera, quienes intentan caracterizar el neo pasan por alto no solo el estudio del contexto, como lo acabamos de señalar, sino las diferentes variantes que se desprenden del término: neoconstitucionalismo teórico, ideológico o metodológico (Comanducci, 2002, p. 75-98). Como ocurre en toda discusión jurídica, de acuerdo a la noción de derecho que asuma serán definidos los conceptos jurídicos. Así, según sea la noción de Constitución que se tenga, será definido el neoconstitucionalismo. Es, en poca palabras, una palabra claramente ambigua y permeada por la mayor o menor emotividad con la que se quiera usar el término «Constitución».

Se puede afirmar que un constitucionalismo ideológico es más proclive a ejercer una defensa de la naturaleza jurídica de los elementos morales (valores) consagrados en el texto de la Constitución, esto es, elevará a norma jurídica un valor aduciendo como razón suficiente su positivización; el metodológico no podrá negar la presencia de esos elementos morales pero se preocupará por analizar o distinguir los elementos morales (valores y principios morales) de los políticos (directrices) y los jurídicos (reglas y principios jurídicos); el constitucionalismo teórico se encargará de describir las transformaciones del derecho ante la presencia de una Constitución con un valor político, moral y jurídico. Resulta complejo intentar una comprensión del constitucionalismo sin abordar sus proyecciones en los tres ámbitos referidos.

A modo de síntesis, se puede resaltar que muchos autores dedicados al estudio del neoconstitucionalismo olvidan que éste

(...) no representa una unidad epistemológica en la medida que alude a aspectos políticos, teóricos y filosóficos que demarcan características distintas según cada contexto constitucional. Ello impide hablar de un solo neoconstitucionalismo y por esta razón se critica aquella noción de neoconstitucionalismo axiológico representado por la presencia de principios y valores que determinan, en opinión de algunos, vínculos necesarios entre la moral y el derecho (Estrada, 2012, p. 513).

En virtud de lo expuesto, se puede expresar, bajo una perspectiva de la Teoría general del derecho forjada en un contexto de imparable constitucionalización, que la noción de neocons- 
titucionalismo que resulta más congruente con los propósitos del constitucionalismo de imponer límites al poder y promover el respeto por los derechos individuales como pilares del Estado social de derecho, es el neoconstitucionalismo metodológico nunca separado pero tampoco identificado con un iuspositivismo metodológico. El constitucionalismo metodológico se preocupará por defender una idea de principios como normas jurídicas, que prevalecen sobre las restantes normas del ordenamiento, que determinan su validez y pertenecen al bloque de constitucionalidad.

En todo caso, la mayor o menor presencia de las características generales del neoconstitucionalismo depende de cada contexto socio político. No es posible explicar de la misma forma el constitucionalismo europeo irradiado por el alemán, que el constitucionalismo suramericano en el que se advierte en casos como el colombiano y el argentino, una fuerte influencia del constitucionalismo anglosajón. Mientras que el constitucionalismo europeo encuentra parte de su historia en el constitucionalismo alemán de posguerra, el constitucionalismo suramericano encuentra una fuerte influencia en el constitucionalismo norteamericano (Serna, 2005, p. XIX).

A modo de conclusión, se puede afirmar que si bien son indiscutiblemente importantes los aportes del constitucionalismo europeo en la definición del neoconstitucionalismo, se incurre en craso error cuando se intenta su estudio al margen de las específicas circunstancias políticas y sociales colombianas. Por ello es necesario ajustar el lente con el cual se va a observar y analizar el neoconstitucionalismo en Suramérica y, en particular, en Colombia.

\section{LA NOCIÓN DE PRINCIPIOS EN EL CONTEXTO COLOMBIANO}

Algo similar a lo que se advirtió en relación al neoconstitucionalismo ocurre con los principios, en la medida en que el estudio de estos está atado a un presupuesto político pocas veces advertido por muchos de sus cultores: la noción de principios, entendidos como garantías, depende de la mayor o menor legitimidad del poder político, en especial, del órgano parlamentario. Así, cuanto mayor confianza inspire menor deberá ser la importancia de los principios, contrario sensu, cuanto menor sea el grado de confianza, mayor deberá ser el peso de los principios como límites al poder o criterios de validez.

Por ello, no estamos de acuerdo con un estudio de los principios fincado exclusivamente en doctrinas foráneas forjadas al margen -y hasta con desconocimiento- del contexto nacional. Propuestas como la de Ronald Dworkin construidas en el contexto del derecho anglosajón o la de Robert Alexy, pensada en un contexto Europeo son, sin duda alguna, importantes, pero claramente insuficientes al momento de determinar el papel de los principios en razonamiento jurídico colombiano.

A la diversidad de sentidos otorgados a la expresión principios, se suma, como ya se señaló, el potpurrí de nociones existentes en el contexto colombiano: principios de derecho natural, normas rectoras, principios generales del derecho, principios constitucionales, etc., y la variedad de funciones reconocidas a los mismos: auxiliares (criterios de interpretación, integración o creación) o principales (normas prevalentes sobre las restantes normas del ordenamiento). Para una mejor comprensión de los principios, en otro espacio realizamos el siguiente esquema que representa las nociones de principios existentes en Colombia y que consideramos de importancia reproducir ahora:

En el contexto colombiano se puede advertir, básicamente, dos posiciones en relación a los principios (se exponen más ampliamente en Estrada, 2010, p. 77-111) que describen las relaciones entre estos y las reglas, a partir de criterios como su naturaleza y sus funciones: una fuerte y otra débil. Ambas sugieren una específica actitud del operador jurídico al momento de aplicar los principios: 
Posición débil. Afirma que los principios no son normas jurídicas sino normas extrasistemáticas, morales, que están por fuera del derecho, que solo ejercen una función auxiliar frente a las normas jurídicas y que solo se aplican en los denominados casos difíciles. Son entendidos, principalmente, como principios de derecho natural. Entre uno de sus principales defensores se puede mencionar a Giorgio del Vecchio (1971, p. 113-125). En Colombia son muestras de esta posición el artículo 4 de la Ley 153 de $1887^{3}$ y la Sentencia de la Corte Constitucional C-083 de 1995, MagistradoPonente Carlos Gaviria Díaz .

Posición fuerte. Esta teoría fuerte de principios asume que forman parte del universo de las normas jurídicas junto con las reglas, en la medida en que son resultado de un proceso de inducción del mismo ordenamiento jurídico. Esta posición fuerte se puede clasificar, a su vez, en dos: una posición fuerte-débil que ve en los principios normas jurídicas pero que solo ejercen funciones subsidiarias, como la de interpretar, integrar y crear derecho. Un

3 Señala: «Artículo 4.Los principios del derecho natural y las reglas de la jurisprudencia servirán para ilustrar la Constitución en casos dudosos. La doctrina constitucional es, a su vez, norma para interpretar las leyes».

4 En esta sentencia la Corte Constitucional de Colombia interpreta la expresión principios generales del derecho del artículo 230 de la CP: «6.2.6. Los principios generales extrasistemáticos. Pero cia qué alude entonces, es ahora la pregunta pertinente, la expresión principios generales del derecho en el contexto del artículo 230 de la Carta de 1991 ? Se trata, entonces, de principios que no satisfacen las condiciones de la regla de reconocimiento y, por ende, no hacen parte del ordenamiento pues no son materialmente reductibles a la Constitución. Según expresión afortunada de Carrió «pueden ser llamados principios jurídicos en cuanto se refieren a aquél (el derecho) pero no en cuanto partes de él», y añade: «el uso judicial de ellos puede conferirles, en el mejor de los supuestos, el rango de candidatos a integrar el sistema, una vez que ese uso adquiera consistencia, regularidad y carácter normativo suficientes como para considerar que las pautas aplicadas son normas jurisprudenciales en vigor o se incorporen al ordenamiento -agrega la Corte- por disposición del legislador» (Corte Constitucional de Colombia, Sentencia C-083 de 1995, MP. Carlos Gaviria Díaz). ejemplo de esta posición es el texto del artículo 230 de la CP que los reconoce como criterios auxiliares; y la posición, la fuerte-fuerte, que señala que los principios son normas jurídicas que priman sobre las restantes normas del ordenamiento.

De las posiciones expuestas consideramos, con apoyo en una sencilla observación de nuestra agreste realidad política y social, y con ayuda de las diferentes opiniones de la comunidad jurídica con la que hemos compartido estas ideas, que la noción de principios que exige nuestro Estado social y constitucional de derecho es la fuerte-fuerte. Estas son las razones: 1. Los principios, como se indicó, son normas jurídicas, las más importantes del ordenamiento, que condicionan la validez de las restantes normas (argumento ontológico); 2. Los principios sirven de principal razón de la decisión o ratio decidendi de las sentencias de las altas cortes (argumento funcional); y, 3. Los principios prevalecen sobre las restantes normas por mandato del mismo legislador (argumento lógico), v. gr. los artículos 13 del Código Penal ${ }^{5}$, 26 del Código de Procedimiento Penal ${ }^{6}, 21$ de la Ley 734 de 20027, 13 de la Ley 836 de

5 «Artículo 13. Normas rectoras y fuerza normativa. Las normas rectoras contenidas en este código constituyen la esencia y orientación del sistema penal. Prevalecen sobre las demás normas e informan su interpretación (subrayado fuera de texto).

6 «Artículo 26. Prevalencia. Las normas rectoras son obligatorias y prevalecen sobre cualquier otra disposición de éste código. Serán utilizadas como fuente de interpretación» (subrayado fuera de texto).

7 «Artículo 21. Aplicación de principios e integración normativa. En la aplicación del régimen disciplinario prevalecerán los principios rectores contenidos en esta ley y en la Constitución Política. En lo no previsto en esta ley se aplicarán los tratados internacionales sobre derechos humanos y los convenios internacionales de la OIT ratificados por Colombia, y lo dispuesto en los códigos Contencioso Administrativo, Penal, de Procedimiento Penal y de Procedimiento Civil en lo que no contravengan la naturaleza del derecho disciplinario» (subrayado fuera de texto). 
$2003^{8}, 5$ de la Ley 1098 de $2006^{9}, 16$ de la Ley 1123 de $2007^{10}$, 3 de la Ley 1306 de 2009'11, 197 numeral 9 de la Ley 1607 de 2012.

El caos que ofrece el estudio de los principios impone, a todo operador jurídico, el mayor esfuerzo posible dirigido a formular una noción de ellos que sea coherente con el contexto colombiano, para lo cual resulta necesario tener como un paso fundamental el estudio de la noción de principios en la Asamblea Nacional Constituyente de Colombia de 1991 y, a partir de allí, perfilar los que podrían ser

8 Artículo 13. Prevalencia de los principios rectores. En la interpretación y aplicación de este reglamento prevalecerán los principios rectores que determinan la Constitución Política, la Ley 734 de 2002 y la presente ley.

9 «Artículo 5. Naturaleza de las normas contenidas en este Código. Las normas sobre los niños, las niñas y los adolescentes, contenidas en este código, son de orden público, de carácter irrenunciable y los principios y reglas en ellas consagrados se aplicarán de preferencia a las disposiciones contenidas en otras leyes» (subrayado fuera de texto)

10 Artículo 16. Aplicación de principios e integración normativa. En la aplicación del régimen disciplinario prevalecerán los principios rectores contenidos en la Constitución Política y en esta ley. En lo no previsto en este código se aplicarán los tratados internacionales sobre Derechos Humanos y deontología de los abogados, y lo dispuesto en los Códigos Disciplinario Único, Penal, de Procedimiento Penal y de Procedimiento Civil, en lo que no contravenga la naturaleza del derecho disciplinario. (subrayado fuera de texto).

11 Artículo 3. Principios: En la protección y garantía de los derechos de las personas con discapacidad mental se tomarán en cuenta los siguientes principios: a) El respeto de su dignidad, su autonomía individual, incluida la libertad de tomar las propias decisiones y su independencia; b) La no discriminación por razón de discapacidad; c) La participación e inclusión plenas y efectivas en la sociedad; d) El respeto por la diferencia y la aceptación de las personas con discapacidad mental como parte de la diversidad y la condición humana; e) La igualdad de oportunidades; f) La accesibilidad; g) La igualdad entre el hombre y la mujer con discapacidad mental; h) El respeto a la evolución de las facultades de los niños y las niñas con discapacidad mental y de su derecho a preservar su identidad. Estos principios tienen fuerza vinculante, prevaleciendo sobre las demás normas contenidas en esta Ley» (subrayado fuera de texto). los rasgos fundamentales de una teoría de principios «a la colombiana».

\section{LOS PRINCIPIOS EN LA ASAMBLEA NACIONAL CONSTITUYENTE}

Partamos de la siguiente hipótesis: en la Asamblea Nacional Constituyente no existió un debate a fondo acerca de la naturaleza y funciones de los principios jurídicos. La importancia reconocida a los mismos se soportó en una razón evidente o en un hecho notorio que indicaba que todo debía partir de los principios como consecuencia de la crisis del órgano legislativo y del exagerado formalismo de la función jurisdiccional ${ }^{12}$.

Una lectura a las gacetas de la Asamblea Nacional Constituyente y a los debates suscitados en el interior de sus comisiones, permite recordar la grave crisis institucional de la época, la que exigió soluciones políticas inmediatas postergando el estudio de los aportes de la teoría principial. Se podría afirmar que el discurso principial resultó ser «altamente sofisticado» y secundario, en relación al interés político del constituyente dirigido a dar solución a los graves problemas institucionales que agobiaban a la nación.

Por esa razón, la construcción de una teoría principial en el contexto colombiano ha sido más resultado de una incipiente y en ocasiones caótica, pero sin duda meritoria, labor doctrinaria y jurisprudencial, más que un propósito del constituyente primario. Es importante recordar lo señalado al inicio del presente escrito, con relación al problema de eficacia de los enunciados constitucionales: las falencias en nuestra cultura jurídica en materia de teoría principial no es atribuible tanto a la

12 Como lo indicaba el constituyente Carrillo, en alusión al respeto supersticioso de la ley: «La sociedad aparece así anegada en legalismo, envuelta y confundida entre reglamentos y litigios. Ese camino nos ha conducido no a la juridicidad sino a la arbitrariedad con leyes» (Carrillo, 1991, p.16). 
misma Asamblea Constituyente como a la actitud refractaria de muchas de las facultades de derecho que hacen eco a una Teoría del derecho de mediados del Siglo XIX, esto es, una teoría descontextualizada.

Se evidenció en el constituyente un claro deseo de renovación política pero inadvirtió las consecuencias de no sentar las bases de una teoría jurídica que le sirviera de herramienta para la efectivización de su proyecto. Ese intento de renovación chocó de frente con el muro levantado por un dogmatismo jurídico tradicionalista que se negó -y aún se niega- a la influencia del constitucionalismo. En otros términos, se olvidó contener la presencia y pervivencia de una dogmática de la Teoría del derecho descontextualizada. Basta citar, como ejemplos, la forma en que muchas facultades enseñan temas tan importantes como la teoría de la norma jurídica y de las fuentes del derecho, a partir de un criterio lógico o estructural (supuesto de hecho, cópula y consecuencia) y de jerarquización, respectivamente.

La demostración de la hipótesis formulada se apoyará en un método de investigación documental soportado en el estudio de todas las gacetas de la Asamblea Nacional Constituyente (144), los rollos de microfilmación del Archivo General de la Nación que consignan los debates referidos al tema de los principios buscados bajo las palabras clave: principios fundantes de la Constitución, principios jurídicos, principios generales del derecho; las propuestas de las comisiones preparatorias de la Asamblea Nacional Constituyente y algunas entrevistas realizadas a ex constituyentes y personas cercanas al proceso constitucional.

El deseo por configurar una carta política que ayudara a la superación de la crisis social e institucional motivó, así se advierte de las diversas fuentes consultadas, reflexiones, principalmente, referidas a la configuración y ejercicio del poder $y$ al establecimiento de garantías individuales frente al mismo. Así, temas como la noción de principios que exige el Estado social, democrático y constitucional de derecho, su carácter de normas fundantes y fundamentadoras del ordenamiento jurídico, el sentido del imperio de la ley, la noción de fuentes del derecho en el Estado social, entre otros, no obtuvieron la suficiente atención. Se podría afirmar que el Constituyente pensó que los cambios en esos tópicos operarían automáticamente a partir de la incorporación de una nueva Constitución.

La ausencia de un consenso en aspectos básicos de Teoría del derecho permite afirmar que se construyó una carta política sin el soporte dogmático-jurídico suficiente (de allí que insistamos en la necesidad de una Asamblea Nacional Jurisprudente). Se prestó más atención a asuntos de naturaleza política que a la racionalidad jurídica. La razón es obvia en la medida en que una Asamblea Constituyente es más un foro político que jurídico. Pertinentes las palabras de la Constituyente María Teresa Garcés Lloreda: «Si bien la Asamblea Nacional constituyente no puede calificarse como un foro jurídico, si tuvo la categoría de un gran foro político, en el cual se defendieron los derechos humanos, los derechos de las minorías, y se dio posibilidad de participación a sectores de la sociedad que jamás habían dispuesto de audiencia para sus inquietudes» (1991, p. 29)

Por parecer obvio que de los cambios políticos se desprenderían los jurídicos, pasó desapercibido el hecho de que los postulados de la nueva Carta Política debían estar dotados de un marco teórico adecuado a la nueva realidad política. Por ejemplo, conceptos como el de ordenamiento, norma, fuentes, entre otros, no pueden seguir siendo explicados de la misma manera que se hacía en el contexto del Estado liberal.

Con este artículo se desea demostrar que el énfasis en el discurso político llevó a un involuntario descuido frente al estudio de los principales aspectos de la teoría jurídica: los principios, lo que ha generado que el uso de los mismos esté mediado por el temor al prevaricato, en la medida en que los jueces aún 
consideran que por mandato del artículo 230 de la CP, están sometidos al imperio de la ley, en tanto que los «principios generales del derecho» son «criterios auxiliares de la actividad judicial».

Expresiones como principios políticos, principios jurídicos, principios generales del derecho, principios del derecho natural, son empleadas por el constituyente, sin que se pueda determinar el significado de las mismas y menos su función dentro del sistema político y el ordenamiento jurídico. La ausencia de un debate constituyente con relación a su significado y uso ha promovido una inercia frente a los principios cuando al día de hoy se afirman no solo como paradigmas del sistema constitucional a la luz de las diferentes concepciones neoconstitucionalistas sino como las principales herramientas jurídicas para limitar el ejercicio del poder.

A la luz de la realidad social colombiana, pasada y actual, que refleja una grave crisis de legitimidad, agobiada para la época de 1991 por la figura del Estado de sitio que dotó de especiales poderes al ejecutivo y lo llevó a la suplantación de las competencias del legislativo y al arrinconamiento de la función jurisdiccional durante un período de cuarenta y un años, se comprende la necesidad de implementar, como lo expresó el constituyente Hernando Londoño Jiménez, unos «límites de hierro a las tentativas totalitarias» ${ }^{13}$.

El diagnóstico es indefectible: una de las causas de los principales problemas de nuestra actual cultura jurídica consiste en una enseñanza del derecho que insiste en la separación entre los fenómenos políticos y los jurídicos, en pro de una mal entendida teoría pura del derecho -confundiendo así la diferencia advertida por Kelsen entre la teoría de un derecho puro con la teoría pura del derecho (1992, p. 32). La nueva carta política se ha enseñado, en términos

13 El Constituyente Londoño formula unos principios del derecho penal como límites constitucionales a la elaboración dogmática del hecho punible y a la política criminal del Estado. (Londoño, 1991, p. 30). generales, bajo los mismos presupuestos teóricos del Siglo XIX. Más concretamente, Colombia estrenó carta política pero no renovó ni en sus aulas ni en los textos de apoyo para la enseñanza de la Teoría del derecho, los conceptos jurídicos que debían servir para la efectivización de sus postulados.

Colombia continuó, por ejemplo, con una idea de derecho que privilegia la opción parlamentaria bajo la imagen del legislador racional, con un modelo de derecho por reglas caracterizado por estos cuatros elementos: norma en vez de valor; subsunción en vez de ponderación, independencia del derecho ordinario en lugar de la omnipresencia de la Constitución y autonomía del legislador sobre los tribunales constitucionales (Alexy, 1994, p. 160). En pocas palabras, se vertió el mejor de los vinos en odres viejos. El problema no es que para esa época no se hubieran adaptado las instituciones jurídicas al nuevo marco político, sino que hayan pasado más de veinte años sin que se haya realizado esa tarea.

Estamos, como lo indica el ex constituyente Esguerra Portocarrero, en mora de realizar esas adaptaciones que deben ser propuestas por la academia ${ }^{14}$. Bien lo expresó la doctora María Cristina Gómez. en entrevista realizada durante el desarrollo de la investigación de la cual deriva este artículo:

(...) en el momento en que se busca un cambio, una transformación en la democracia y se comienza a hablar del discurso de la paz, nadie visualizó que paralelo a ese proceso debía haber un proceso de revisión del derecho... es probable que sea necesario liderar un proceso de reflexión de que es el derecho en Colombia porque no lo hemos hecho... hay que tratar de hacer una pequeña mediana teoría del contexto, cierto, y eso lo deben propiciar

14 Así lo manifestó en entrevista conferida en desarrollo de la investigación. 
particularmente los profesores de las facultades de derecho y los estudiantes.

La confianza depositada en los principios se advierte cuando se expresa que son medios de contención de la arbitrariedad del poder del Estado, función que solo pueden cumplir los principios cuando se asumen como normas jurídicas a las cuales debe supeditarse toda la actividad del Estado. Señala el constituyente Hernando Londoño Jiménez:

\section{(...) aspiramos a que se consagren normas} constitucionales que en el futuro impidan este desbordamiento de las facultades al Ejecutivo con motivo del Estado de Sitio. Pero también, en previsión de que ello pueda ocurrir en el futuro, aspiramos a que se eleven a rango constitucional todos los principios, todos los derechos y garantías que en materia penal y de procedimiento han sido abiertamente violados con la legislación de emergencia, como lo hacen las constituciones más modernas, las Cartas Fundamentales inspiradas en las corrientes liberales y democráticas del derecho contemporáneo (Londoño, 1991, p. 10).

Este mismo constituyente manifestó, haciendo relación a los principios, que en la «Constitución Nacional deben consagrarse unos límites de hierro a las tentativas totalitarias» $y$ fungen de "límites constitucionales que se impondrían a la elaboración dogmática del Hecho punible y de la Política Criminal del Estado» (Londoño, 1991, p. 30).

Merece especial mención el escrito de Planteamientos y propuestas ante la Asamblea Nacional Constitucional presentado por la Corte Suprema de Justicia, en el que se advierte la importancia de los principios generales como medios de protección de los derechos humanos y se recomienda como mecanismo para la protección de los mismos el desarrollo de una «definición constitucional de la dogmática de los derechos del hombre y de los principios que conforman las garantías» (Corte Suprema de Justicia, marzo 22 de 1991, p. 23).

La importancia de los principios se hace evidente en la exposición de motivos en ponencia titulada El trabajo como valor fundamental, presentada por los constituyentes Guillermo Perry, Horacio Serpa y Eduardo Verano. Expresan: «No sobra señalar que, cualquiera que sea la naturaleza y jerarquía que dentro de las fuentes normativas se le reconozca a los denominados principios fundamentales $y$ a los elementos esenciales del Estado, es lo cierto que por su prioridad política y lógica ellos no podrán ser ignorados por el intérprete de las normas que en su conjunto integran el ordenamiento jurídico» (Perry, Serpa \& Verano, 1991, p. 2).

Estos mismos constituyentes afirman la importancia de elevar a rango constitucional unos principios que no están consagrados en el texto de la Constitución:

A pesar de que la mayoría de estos derechos, libertades y principios se encuentran consagrados de alguna forma en la Carta Política, a excepción de los derechos políticos, cuya carencia ha sumido el país en lamentables y profundos estados de violencia política, económica y social, hay otros, que no han sido elevados al rango constitucional que les corresponde, ni enunciados claramente para que puedan ser comprendidos por los ciudadano (Perry, Serpa \& Verano, 1991, p. 18).

Aunque un amplio sector de la Asamblea compartía la importancia que debía dársele a los principios, existieron voces que dieron a entender que la consagración de los mismos no era una labor constitucional sino que debían ser definidos en los mismos códigos de procedimiento con la ayuda de los «tratadistas». Expresó el constituyente Echeverry Uruburo:

Los principios propuestos por la Comisión IV, además de su carácter discutible con 
respecto a su inclusión en el texto constitucional, presentan una confusión entre principios orientadores y de naturaleza de la función pública de la justicia y de normas organizacionales, comunes a cualquier estructura organizativa (permanencia, independencia, descentralización...). Dichos principios no pueden ser definidos en la Constitución. Ello, es más propio de un Código Procedimental y de la acción de los tratadistas que de una Constitución" (Echeverry, 1991, p. 15).

Similar posición asumió el Gobierno al oponerse, luego de manifestar su acuerdo con la incorporación de los principios de transparencia, celeridad, gratuidad, autonomía administrativa y presupuestal, descentralización, motivación, libertad personal, favorabilidad, solidaridad, dignidad humana, a la consagración de todas las normas referidas a Principios de derecho penal y las que aluden a los Principios Mínimos de Derecho Penal, «por ser ellas expresión de una de las múltiples escuelas que hay dentro del Derecho Penal, lo que es antitécnico» (Gobierno Nacional, 1991, p. 17).

No obstante las opiniones en el sentido de que los principios no deben estar consagrados en el texto de la Constitución, el deseo del constituyente por hacer de ellos límites al ejercicio del poder del Estado, en especial de la función jurisdiccional, se evidencia en el discurso de clausura de la Asamblea Nacional Constituyente presentado por el Presidente de la Asamblea Álvaro Gómez Hurtado: «Hemos aprobado principios jurídicos que no solo hacen más eficaz la administración de justicia, sino que la vuelven confiable, porque con ellos impediremos sus desmanes» (Gómez, 1991, p. 35).

En definitiva, las diferentes funciones conferidas a los principios y los precarios debates generados en torno a ellos, confirma la necesidad de la aproximación realizada a la noción de principios jurídicos a la luz del especial contexto de Estado social y constitucional de derecho colombiano.

\section{A MODO DE CONCLUSIONES ¿QUÉ HACER?}

El principal objetivo del presente artículo consistió en determinar la posición del Constituyente con relación a los principios jurídicos, al ser considerados estos como principal paradigma normativo del Estado social de derecho. A pesar de su importancia, en el proceso constituyente de 1991 no existió un debate en torno a la naturaleza y funciones que ellos debían cumplir como límites al ejercicio del poder y medios para el restablecimiento del equilibrio entre los poderes públicos, tras cuarenta y un años de aplicación de la figura del Estado de sitio. En razón a ello, se puede afirmar que la teoría de los principios jurídicos no fue ampliamente conocida por el constituyente y que la misma ha ingresado al contexto nacional gracias a una posterior labor jurisprudencial y doctrinal, importante pero a la vez caótica e incipiente a la luz del contexto colombiano.

Ese precario desconocimiento se hizo evidente cuando en el texto de la Constitución Política de 1991 se consagró que los principios generales del derecho cumplían una función auxiliar, sin advertir las nefastas consecuencias para el fortalecimiento de un razonamiento jurídico acorde a las exigencias del Estado social. Ello dio lugar a una interesante paradoja a la que no se le ha sabido sacar el suficiente provecho: ha sido el legislador, en lugar del constituyente y la misma Corte Constitucional, quien ha mostrado más interés en ceder espacio a la ley en favor de la prevalencia de los principios, al reconocerlos como normas prevalentes (de superior jerarquía material) sobre las restantes normas del ordenamiento. La presencia de leyes que reconocen esa condición prevalente permite afirmar que estamos frente a un legislador principialista.

La poca claridad del constituyente con relación a la naturaleza y funciones de los principios, aunada a los precarios (y en ocasiones caóticos) desarrollos jurisprudenciales y doctrinarios, son circunstancias que exigen tomar el testimonio de manos de los más importantes cultores de la principialística, con el fin de adaptar sus 
aportes a la luz del contexto nacional. Dos podrían ser las acciones dirigidas al estudio y fortalecimiento de un razonamiento jurídico principial en nuestro Estado social de derecho: la primera, sería la incorporación de la materia principialística a los planes de estudios de las facultades de derecho o, como mínimo, la actualización del marco teórico que aún se soporta en una idea de derecho decimonónica y que es replicada en la enseñanza de la Teoría general del derecho y del Derecho constitucional; la segunda, el abandono de un neoconstitucionalismo ideológico y de la noción de principios como normas morales.

Finalmente, la siguiente propuesta puede resultar extraña -para algunos absurda- en la medida en que no se conoce registro de algo similar dentro del derecho comparado: teniendo presente que el importante proceso político de 1991 no fijó las herramientas conceptuales jurídicas que le ayudarían a llevarlo a cabo, estimamos necesario y pertinente generar conciencia acerca de la necesidad de una Asamblea Nacional Jurisprudente en la que todas las universidades (tanto las del «eje» como las de «provincia»), colegios de abogados, de jueces y fiscales, grupos de investigación, clínicas jurídicas, etc. sumen esfuerzos para la generación, desde el conocimiento de toda la realidad nacional, de las bases conceptuales mínimas (con respeto de la autonomía universitaria) sobre las cuales se debe soportar la administración de justicia y la formación de los futuros abogados.

\section{REFERENCIAS}

Alexy, R. (1993). Teoría de los derechos fundamentales. (E. Garzón, Trad.). Madrid: Centro de Estudios Constitucionales.

Alexy,R. (1994). El Concepto y la Validez del Derecho. ( J. M. Seña, Trad.). Barcelona: Gedisa.

Aragón, M. (1997) El juez ordinario entre legalidad y constitucionalidad. Bogotá: Instituto de Estudios Constitucionales Carlos Restrepo Piedrahita.
Bernal, C. (2007). El principio de proporcionalidad y los derechos fundamentales (3 Ed.). Madrid: Centro de Estudios Políticos y Constitucionales.

Blanco, R. (1998). El valor de la Constitución. Madrid: Alianza.

Carrillo. F. (1991, Abril). Gaceta Constitucional de la Asamblea Nacional Constituyente de la República de Colombia, 31, 16.

Comanducci, P. (2003). Formas de (NEO) constitucionalismo: un análisis metateórico. En Carbonell, M. (Ed.). Neoconstitucionalismo (s). Madrid: Trotta.

Corte Constitucional de Colombia. Sentencia T-406 de 1992 (MP. Ciro Angarita Barón).

Corte Constitucional de Colombia. Sentencia C-083 de 1995 (MP: Carlos Gaviria Díaz).

Corte Constitucional de Colombia. Sentencia C-067 de 2003 (MP.Marco Gerardo Monroy Cabra).

Corte Suprema de Justicia (1991, Marzo 18). Planteamientos y propuestas ante la Asamblea Nacional Constitucional. Gaceta Constitucional de la Asamblea Nacional Constituyente de la República de Colombia, 22, 23.

Del Vecchio, G. (1971). Los principios generales del derecho ( $3^{a}$ ed.). (J. Ossorio, Trad.). Barcelona: Bosch.

Dworkin, R. (1984). Los derechos en serio. (M. Guastavino Trad.). Barcelona: Ariel.

Echeverry, U. (1991, Septiembre 9). Gaceta Constitucional de la Asamblea Nacional Constituyente de la República de Colombia, 123, 15.

Estrada, S. (2010). La ponderación o la débil frontera entre la arbitrariedad y el uso legítimo de la discrecionalidad. Vniversitas, 21, juniodiciembre de 2010. 
Estrada, S. (2012). Filosofía del derecho y neoconstitucionalismo. En A. Botero (Ed.). Filosofía del derecho. Medellín: Universidad de Medellín.

Garcés, M. (agosto 6, 1991). Gaceta Constitucional de la Asamblea Nacional Constituyente de la República de Colombia, 118, 29.

García, A. (2003). La teoría del derecho en tiempos del constitucionalismo. En M. Carbonell (Ed.). Neoconstitucionalismo (s). Madrid, Trotta.

Gobierno Nacional (1991, Septiembre 9). Gaceta Constitucional de la Asamblea Nacional Constituyente de la República de Colombia, 123, 17.

Gómez, A. (julio 7, 1991). Discurso de clausura de la Asamblea Nacional Constituyente. Gaceta Constitucional de la Asamblea Nacional Constituyente de la República de Colombia, 114, 35.

Ferrajoli, L. (2001). Derechos y garantías, (2a Ed). (P. Ibañez, A. \& Greppi, Trads.). Madrid: Trotta.

Habermas, J. (1998) Facticidad y Validez. (M. Jiménez, Trad). Madrid: Trotta.

Kelsen, H. (1992). Qué es la Teoría Pura del Derecho. (E. Garzón, Trad.). México: Fontamara.

Kelsen, H. (1995). ¿Quién debe ser el defensor de la Constitución? (R. Brie, Trad) Madrid: Tecnos.

Kelsen, H. (2008) La garantía jurisdiccional de la Constitución (la justicia constitucional). (R.
Tamayo, Trad). Revista Iberoamericana de Derecho Procesal Constitucional, 10, julio-diciembre.

Londoño, H. (marzo 21, 1991). Gaceta Constitucional de la Asamblea Nacional Constituyente de la República de Colombia, 25, 30.

Londoño, H. (abril 8, 1991) Gaceta Constitucional de la Asamblea Nacional Constituyente de la República de Colombia, 39, 10.

Lopera, G. (2007). Principio de proporcionalidad y ley penal. Madrid: Centro de Estudios Políticos y Constitucionales.

Lopez, D. (2004). Teoría impura del derecho. Bogotá: Legis.

Perry, G., Serpa, H., \& Verano, E. (1991, Marzo 19) El trabajo como valor fundamental. Gaceta Constitucional de la Asamblea Nacional Constituyente de la República de Colombia, 23, 2.

Perry, G., Serpa, H., \& Verano, E. (marzo 20, 1991). Gaceta Constitucional de la Asamblea Nacional Constituyente de la República de Colombia, 24, 18.

Prieto, L. (2003) Neoconstitucionalismo y ponderación judicial. En:M. Carbonell (Ed.). Neoconstitucionalismo (s). Madrid: Trotta.

Serna,P. (2005) Presentación al texto La Constitución como orden de valores. Cruz. M. Luis. Granada: Comares.

Valencia, H. (2007). Nomoárquica, principialística jurídica o filosofía y ciencia de los principios generales del derecho, $\left(4^{a} \mathrm{Ed}\right)$. Medellín: Comlibros. 